\title{
An examination of the \#NGSSchat Storify database
}

\author{
Conrad Borchers, ${ }^{1}$ Joshua M. Rosenberg, ${ }^{2}$ Christian Fischer ${ }^{1}$ \\ ${ }^{1}$ University of Tübingen, Germany \\ ${ }^{2}$ University of Tennessee, Knoxville, United States of America
}

Abstract: Teachers frequently use Twitter to engage in professional learning activities. A prominent example of teachers' use of Twitter for such purposes is evident within the \#NGSSchat community, which encouraged synchronous (at the same time) conversations between teachers and other educational stakeholders regarding the Next Generation Science Standards (NGSS) curriculum reform in the United States. Notably, \#NGSSchat moderators archived the chats via the Storify platform, which has subsequently been used by researchers to understand science teachers' professional learning activities on Twitter. However, what has not been established is the representativeness of this archive of \#NGSSchat tweets. In other words, whether those who archived \#NGSSchat content selected only a (potentially biased) selection of tweets is as yet unknown. Thus, in this study, we examined the Storify \#NGSSchat database and compared it with raw data requests using the Twitter API. We found that the synchronous chats most data was adequately achieved. Contrarily (but as anticipated given what distinguishes the \#NGSSchat community-synchronous conversations), the Storify \#NGSSchat database did not capture most data outside these synchronous chat sessions. Importantly, we did not find an indication of systematic content- or user-driven tweet exclusion within the synchronous NGSS chat sessions on Storify, suggesting that the \#NGSSchat archive via Storify (and potentially others like it) may be used by researchers for most research-related purposes. 


\section{An examination of the \#NGSSchat Storify database}

\section{Introduction}

In times of rapid technological development online learning is gaining popularity across all domains in the educational landscape. Teacher education is no exception, with many online professional development (PD) activities being offered to and adopted by teachers (e.g., Dede et al., 2016). In particular, online teacher communities on social networking sites provide opportunities for informal teacher learning (e.g., Greenhow \& Lewin, 2016; Greenhow et al., 2018). As costs and proximity of learning opportunities (e.g., McCoy et al., 2020) are important factors in teachers' PD selection, online communities seem appealing for engaging in professional learning. Notably, research examining the effectiveness of online teacher communities related to the Advanced Placement program found positive associations for teachers participating in online teacher communities on student performance (Fishman et al., 2014; Frumin et al., 2018). Besides these more formal online communities that are hosted from institutional stakeholders, teachers also self-organize on social networking sites such as Facebook (e.g., Ranieri, Manca, \& Fini, 2012), Pinterest (e.g., Hu et al., 2018), Reddit (e.g., Staudt Willet \& Carpenter, 2020), Twitter (e.g., Carpenter \& Krutka, 2019; Fischer et al., 2019, Rosenberg et al., 2016), and others. Especially during early phases of curriculum reforms, when teachers may be looking for guidance in implementing reform, convenient access to opportunities for professional learning play an important role in successful reform efforts (Stiles et al., 2017).

This can also be seen in one of the largest curriculum reforms in the United States in recent years, the Next Generation Science Standards (NGSS; NGSS Lead States, 2013). In response, teachers (and other stakeholders, such as school- and school district-based 
administrators) started organizing themselves on Twitter to discuss the reform, share ideas on potential instructional enactments, and to connect with one another. One of the most prominent hashtags used by teachers to discuss the NGSS was \#NGSSchat (Carpenter et al., 2020). Teachers would set up a certain time to virtually meet up on Twitter, often in a bi-monthly frequency, and to discuss a certain topic in a synchronous fashion. Afterwards, the moderators of the \#NGSSchat community chose to archive the chats on the Storify platform (http://www.ngsspln.com/ngsschat.html). Notably, the Storify platform itself is not active anymore and the database is only readily accessible through our versions of it (see Rosenberg et al., 2020, to access this data). Data from Storify has been used in several research projects (e.g., Rosenberg et al., under review). As this moderator-filtered approach to store Twitter data may have led to biased selection of tweets (e.g., removing presumably unwanted content, favoring tweets from more prominent users, tweets that received more likes/retweets, etc.), the purpose of this paper is to explore the quality and quantity of this Storify database. Thus, the core research question is as follows: How does the Storify \#NGSSchat database compare to raw \#NGSSchat data requests?

\section{Methods}

\section{Storify database between \#NGSSchat synchronous sessions}

In order to evaluate the completeness of the Storify data between NGSS chat sessions, we extracted all timeframes from the Storify database in between no tweets were posted in 2014, 2015, and 2016. We then ordered these timeframes by size and started to download them beginning with the greatest gap in the Storify data. These time gaps were then ordered identifying 48 gaps with more than six hours between tweets in the Storify \#NGSSchat. The timeframes of these 48 gaps were then used to download tweets using the search_fullarchive() 
function from the R-package rtweet (Kearney, 2019). Afterwards we compared quantitative tweet characteristics (i.e., number of favorites and retweets) for the Storify data and the missing data between the synchronous NGSS chat sessions. The entire code used to conduct this analysis is included as an RMarkdown file in the appendix and to the repository.

\section{Storify database within \#NGSSchat synchronous sessions}

In order to evaluate the completeness of the Storify data within NGSS chat sessions, we examined 9 random NGSS chat sessions (3 for each year). Therefore, the Storify data was divided into time frames of 24 hours that equaled a day in UTC time format. Then, all timeframes that consisted of at least 300 tweets were identified (10 days in 2014, 18 days in 2015, 5 days in 2016). This procedure ensured that we did not randomly select a day without a synchronous NGSS chat session. Afterwards, we randomly selected three days for each 2014, 2015 and 2016. For each of these nine timeframes, tweets were downloaded using the aforementioned method. This new downloaded data was then employed to assess the completeness of the Storify database within the synchronous chat sessions and investigated potential reasons for why data was missing. The entire code used to conduct this analysis is included as an R-markdown file in the appendix.

\section{Results}

\section{Completeness of Storify data between \#NGSSchat synchronous sessions}

The original Storify database consisted of 17,226 tweets posted under the hashtag \#NGSSchat between 2014 and 2016. The identification of time gaps results in 48 gaps that were greater than 6 hours (Figure 1). We considered this as sufficient, as we obtained less than 40 new tweets for the smallest three timeframes. The 48 download queries resulted in a total of 33,097 tweets. This estimate indicates that the Storify database consists of $34.2 \%$ of all tweets that could 
have been obtained between 2014 and 2016 at highest. Notably, the chronologically latest of these gaps (the time gap between May 2016 and the end of 2016) amounted to 16,689 missed tweets in the Storify database, including full NGSS chat sessions. If this time gap were to be excluded from the calculation of the completeness of the Storify database, Storify would have a $51.2 \%$ completeness rate.

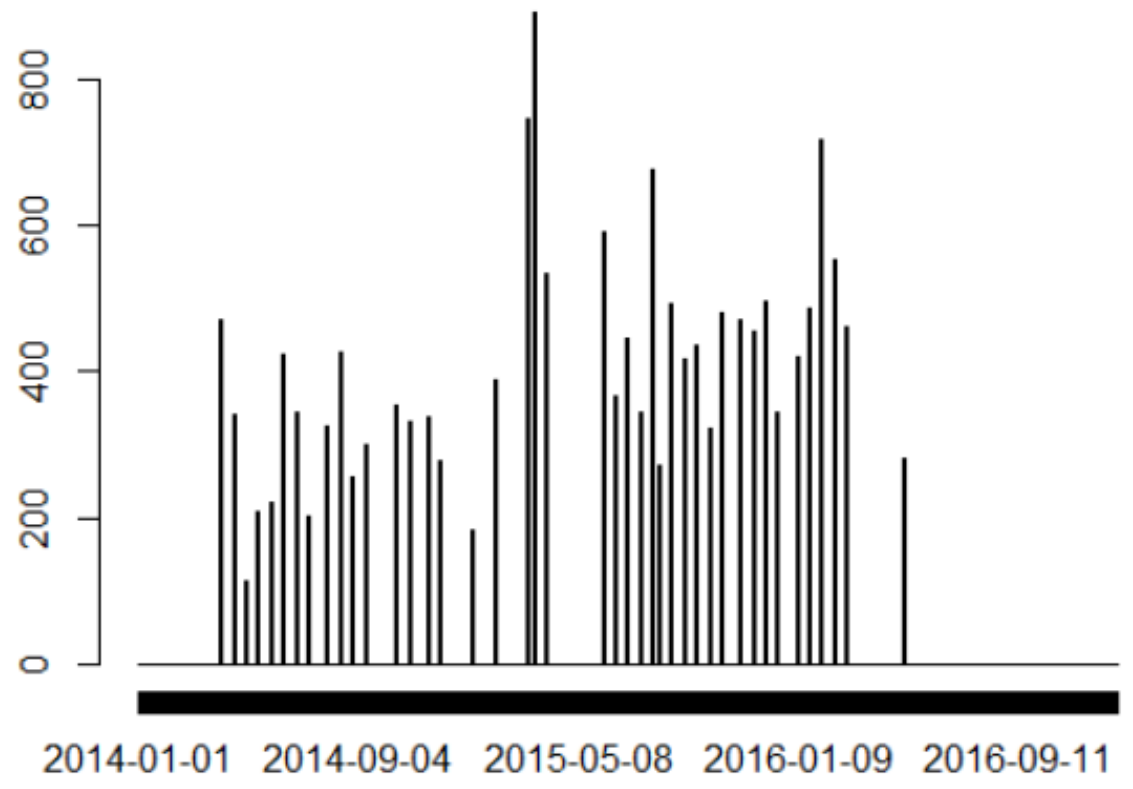

Figure 1. Number of tweets in Storify database for each day of the years 2014, 2015, and 2016.

Comparing the Storify database with the additional tweets that were obtained in between NGSS chat sessions, we investigated possible differences concerning favourite and retweet counts. The Storify database had a mean favourite count of $M=1.20, S D=1.75$, ranging from 0 to 38 while the additional tweets had a mean favourite count of $M=0.93, S D=2.66$, ranging from 0 to 248. Meanwhile, the Storify database included a mean retweet count of $M=0.35, S D=$ 1.04, ranging from 0 to 53 while the additional tweets included a mean retweet count of $M=$ $0.43, S D=1.93$ ranging from 0 to 198. 


\section{Completeness of Storify data within \#NGSSchat synchronous sessions}

To examine the completeness of the Storify database within the NGSS chat sessions, we randomly selected three days for each year 2014, 2015 and 2016 that consisted of at least 300 tweets. Out of all 44 distinct days that were included in the Storify database, 33 day fulfilled this criterion, making up $68.8 \%$ of all days represented in the Storify database. The resulting nine days were downloaded and compared with the original data.

Overall, while the Storify database included 3,960 tweets, the re-download data yielded 6,263 tweets during these nine days. Assuming that no tweets were deleted between the two points of download, that would mean that the Storify database during these nine days would only be complete to $63.2 \%$. Evaluating this assumption, we found that 43 tweets within the nine days were deleted from the Storify database such that they were not obtained through re-downloading. This makes up for $1.1 \%$ of tweets in the Storify database being deleted prior to our re-download. Assuming that these 43 would not have been deleted but rather re-downloaded, the aforementioned first estimate of the completeness of the Storify database amounts to $62.8 \%$.

We considered that this discrepancy of $36.8 \%$ between the Storify database and the redownloaded tweets within the selected nine days is due to the fact that we looked at 24 hour time frames rather than the NGSS chat sessions only. We therefore only looked at the two hours with most tweets in the Storify database (Figure 2), 1 and 3 AM UTC. Such an exclusion was achieved through filtering all tweets posted between 01:00 and 02:59 AM UTC by extracting the hour of the creation date of all tweets. This leads to an estimated completeness of the Storify database of $67.5 \%$ within NGSS chat sessions and indicates that the aforementioned discrepancy in data completeness seems to also hold true within NGSS chat sessions. On the other hand, when excluding retweets from the sample the completeness of the Storify database was estimated 
at $80.8 \%$. When additionally only looking at tweets posted between 1 and 3 AM UTC that were not retweets, the completeness of the Storify database was estimated at $84.0 \%$.

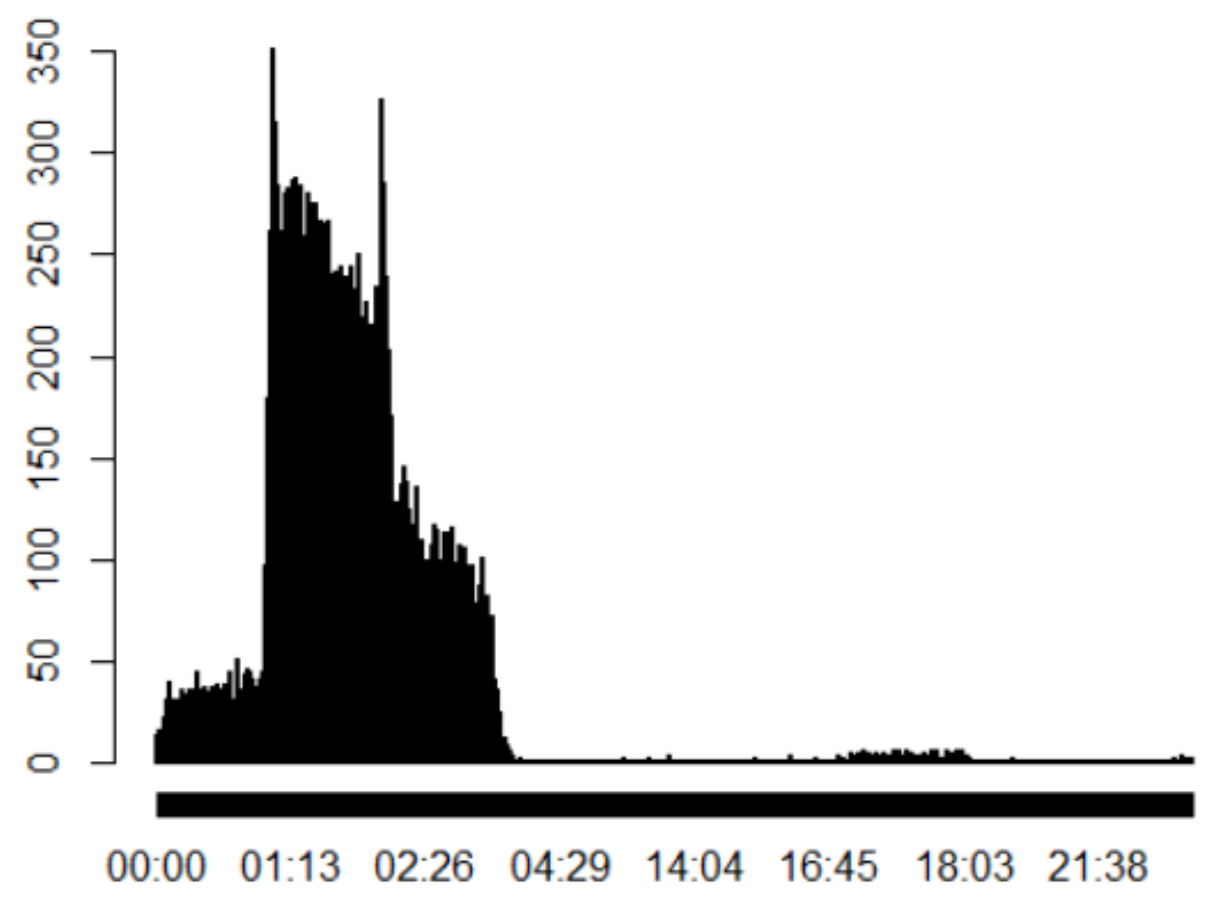

Figure 2. Number of tweets in Storify data over time (UTC) by minutes of the day.

Identifying patterns of missing tweet data. Tweets in the Storify database were filtered from Storify moderators by certain criteria. As the Storify database within NGSS chat sessions seemed more complete when excluding retweets and tweets posted outside of 1 and 3 AM UTC, we examined these criteria. We found that while $60.4 \%$ of tweets that were excluded were retweets, only $1.1 \%$ of tweets in the Storify database were retweets. This seems to indicate that retweets were viewed as an exclusion criterion. Similarly, $22.3 \%$ of excluded tweets were not posted between 1 and 3 AM UTC while only $4.3 \%$ of tweets that were not excluded were not posted between 1 and 3 AM UTC. Together, 69.5\% of all excluded tweets that can be explained by either being a retweet, being posted outside of 1-3 AM UTC or being both. Thus, we excluded all tweets that were retweets or posted outside of 1 and 3 AM UTC for all subsequent analysis 
and further examined tweets in our re-downloaded sample to identify possible properties that could qualify as exclusion criteria.

Another potential exclusion criteria might be to exclude short tweets (with the assumption that they may not have sufficient content; e.g., "@ Individual1 No limits? Tell me more. ...\#NGSSchat"). Examining the length of tweets of the mentioned subset, we obtained a mean character length of $\mathrm{M}=91.57, \mathrm{SD}=35.83$, ranging from 23 to 151 . For the length of tweets during the sampled days in the Storify database we obtained $\mathrm{M}=98.09, \mathrm{SD}=33.54$, ranging from 18 to 151 . The length of tweets therefore seemed not to be a possible filtering criterion for Storify moderators.

Another possibility is that certain users were systematically excluded. We found that 17 users did not appear in the Storify database who contributed a total of only $3.4 \%$ missing tweets. Notably, none of the excluded users contributed more than four tweets. Thus, it seems unlikely that certain users were systematically excluded by Storify moderators.

Creating a full chronological list of tweets that were excluded while meeting the criteria of not being retweets and being posted between 1 and 3 AM UTC, we looked at further criteria of exclusion ourselves as algorithmic solutions seemed to not lead to any further explanation of exclusion criteria. Firstly, we found that some NGSS chat sessions started at 2 AM UTC and were preceded by a chat session called "High School NGSS chat" which included the hashtag \#NGSSchat as well. These chat sessions were always excluded in the described subset and made up 302 tweets. The exclusion of tweets posted within HS NGSS chat sessions can therefore explain an additional $12.9 \%$ of all excluded tweets in our re-downloaded sample. Similarly, we found that many excluded tweets represented introductions of teachers and reactions to these introductions in the beginning of NGSS chat sessions (e.g., "Hi @username, great to see you!", 
"Jane Doe here, teaching Chemistry in New York"). We counted 118 of these tweets in the described subset such that additional 5.0\% of all excluded tweets can be explained through excluded greetings and introductions of teachers. Also, we found that very short reactions like “Agreed. Thanks@username”were excluded 11 times, explaining additional 0.5\% of exclusions. Thus, with these additional checks added to the other exclusion criteria we identified; we could explain $87.9 \%$ of all excluded tweets within our re-downloaded sample of NGSS chat sessions.

For the remaining $12.1 \%$, we could not identify any consistent pattern that may explain exclusion criteria. For example, when re-examining the length of tweets as an exclusion criterion on theis small subset, these remaining $12.1 \%$ of tweets had a mean length of $\mathrm{M}=92.47$ characters, $\mathrm{SD}=33.48$, ranging from 23 to 148 , yet again similar to the tweets that were not excluded. It seems that these $12.1 \%$ of tweets were excluded by moderators seemingly at random when considering the entire Storify database. Also, there have been some inconsistencies in the enforcement of the aforementioned exclusion criteria. For instance, $1.1 \%$ of tweets during the sampled days in the Storify database were still retweets even though retweets seem to constitute an exclusion criterion. Also, we found that while introduction and greeting tweets were almost always excluded in some NGSS chat sessions, they were not excluded in other NGSS chat sessions (in our sample: all sessions that took place on January 22nd, 2016 or later). Such inconsistencies in tweet exclusion of tweets by NGSS moderators limit the ability to clearly identify further exclusion criteria.

\section{Conclusion}

Within the chat sessions, the Storify dataset includes about $80 \%$ of all original tweets. Out of the missing $20 \%$, tweets mostly belonged to the "High School NGSS chat" sessions 
(\#hsNGSSchat) and included teachers introducing themselves or greeting each other. The exclusion of those tweets do not seem to harm the validity of analyses utilizing Storify data or introduce biases to potential analyses. The remaining approximate $10 \%$ of tweets in the Storify database seem to be missing at random. When examining quantitative tweet characteristics (number of favorites, retweets), we did not see substantial differences between the Storify database and the newly downloaded data between the synchronous NGSS chat sessions. The Storify data does not include data in between NGSS chat sessions (about 50\% of tweets are missing between January 2014 and April 2016). Thus, we do not recommend using the Storify database for examining activity outside the synchronous NGSS chat session. In summary, the Storify data may be utilized to understand the synchronous NGSS chat sessions as it captures the most of the relevant tweet activity. That said, a redownload of the entire \#NGSSchat community may be recommended if analyses intend to capture the full range of interactions within the NGSS chat session without the content filtering provided by the Storify moderators. 


\section{References}

Carpenter, J. P., \& Krutka, D. G. (2014). How and why educators use Twitter: A survey of the field. Journal of Research on Technology in Education, 46, 414-434, doi:10.1080/15391523.2014.925701

Carpenter, J., Tani, T., Morrison, S., \& Keane, J. (2020). Exploring the landscape of educator professional activity on Twitter: an analysis of 16 education-related Twitter hashtags. Professional Development in Education, 1-22.

https://doi.org/10.1080/19415257.2020.1752287

Dede, C. Eisenkraft, A., Frumin, K. \& Hartley, A. (2016), Teacher learning in the digital age: Online professional development in STEM education. Cambridge, MA: Harvard Education Press.

Fischer, C., Fishman, B., \& Schoenebeck, S. (2019). New contexts for professional learning: Analyzing high school science teachers' engagement on Twitter. AERA Open, 5(4), 1-20. https://doi.org/10.1177/2332858419894252

Fishman, B., Fischer, C., Kook, J., Levy, A., Jia, Y., Eisenkraft, A., McCoy, A., Lawrenz, F., Dede, C., \& Frumin, K. (2014, April). Professional development for the redesigned AP Biology exam: Teacher participation patterns and student outcomes. Paper presented at the 2014 annual meeting of the American Educational Research Association, Philadelphia, PA.

Frumin, K., Dede, C., Fischer, C., Fishman, B., Eisenkraft, A., Foster, B., Levy, A., Lawrenz, F., \& McCoy, A. (2018). Adapting to large-scale changes in Advanced Placement biology, chemistry, and physics: The impact of online teacher communities. International Journal of Science Education, 40(4), 397-420. https:/doi.org/10.1080/09500693.2018.1424962 
Greenhow, C., Campbell, D., Galvin, S., \& Askari, E. (2018). Social media in teacher professional development: A literature review. In E. Langran \& J. Borup (Eds.), Proceedings of Society for Information Technology \& Teacher Education International Conference (pp. 2256-2264). Washington, D.C., United States: Association for the Advancement of Computing in Education (AACE).

Greenhow, C. \& Lewin, C. (2016) Social media and education: reconceptualizing the boundaries of formal and informal learning, Learning, Media and Technology, 41(1), 6-30, doi: $10.1080 / 17439884.2015 .1064954$

Hu, S., Torphy, K. T., Opperman, A., Jansen, K., \& Lo, Y.-J. (2018). What do teachers share within socialized knowledge communities: A case of Pinterest. Journal of Professional Capital and Community, 3, 97-122.

Kearney, M. W. (2019). rtweet: Collecting Twitter Data. R package version 0.6.9. Retrieved from https://cran.r-project.org/package=rtweet

McCoy, A., Levy, A., Frumin, K., Lawrenz, F., Dede, C., Eisenkraft, A., Fischer, C., Fishman, B., \& Foster, B. (2020). From the inside out: Teacher responses to the AP curriculum redesign. Journal of Science Teacher Education, 31(2), 208-225. https://doi.org/10.1080/1046560X.2019.1685630

NGSS Lead States. (2013). Next generation science standards: For states, by states. Washington, DC: Achieve, Inc. (On behalf of the twenty-six states and partners that collaborated on the NGSS).

Ranieri, M., Manca, S., \& Fini, A. (2012). Why (and how) do teachers engage in social networks? An exploratory study of professional use of Facebook and its implications for 
lifelong learning. British Journal of Educational Technology, 43, 754-769. doi:10.1111/j.1467-8535.2012.01356.x

Rosenberg, J. M., Reid, J. W., Dyer, E., Koehler, M., Fischer, C., \& McKenna, T. J. (2020) Analysis and data accompanying "Idle chatter or compelling conversation? The potential of the social media-based \#NGSSchat network as a support for science education reform efforts". https://osf.io/9ex7k/

Rosenberg, J. M., Reid, J. W., Dyer, E., Koehler, M., Fischer, C., \& McKenna, T. J. (under reviews). Idle chatter or compelling conversation? The potential of the social mediabased \#NGSSchat network as a support for science education reform efforts. Journal of Research in Science Teaching.

Rosenberg, J. M., Greenhalgh, S. P., Koehler, M. J., Hamilton, E. R., \& Akcaoglu, M. (2016). An investigation of state educational Twitter hashtags (SETHs) as affinity spaces. Elearning and Digital Media, 13(1-2), 24-44.

Staudt Willet, K. B., \& Carpenter, J. P. (2020). Teachers on Reddit? Exploring contributions and interactions in four teaching-related subreddits. Journal of Research on Technology in Education, 52(2), 216-233. https://doi.org/10.1080/15391523.2020.1722978

Stiles, K. E., Mundry, S. E., \& DiRanna, K. (2017). Framework for leading next generation science standards implementation. San Francisco, CA: WestEd. 


\title{
Appendix
}

\author{
2020-05-15
}

\section{Example of downloading tweets using rtweet}

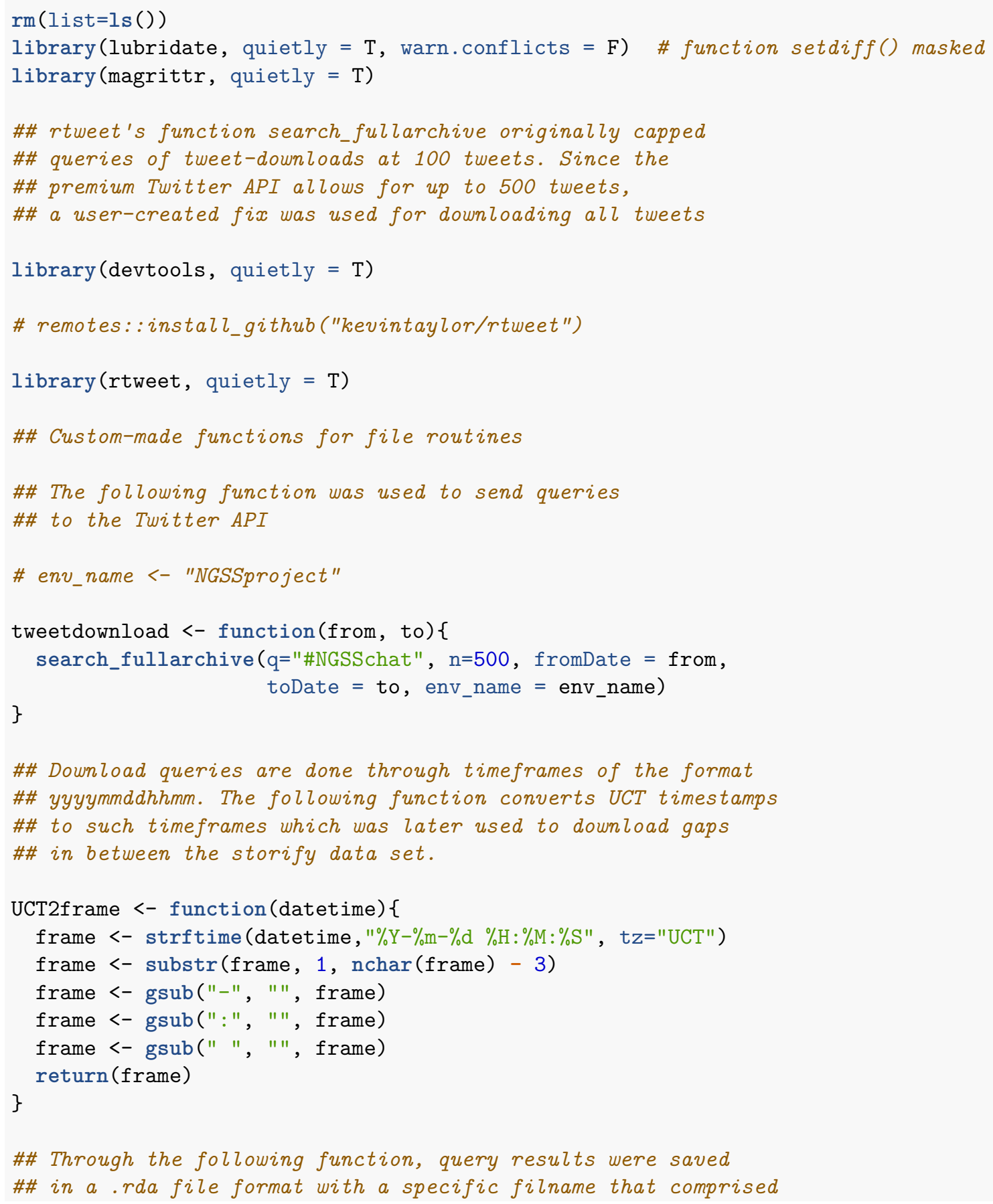




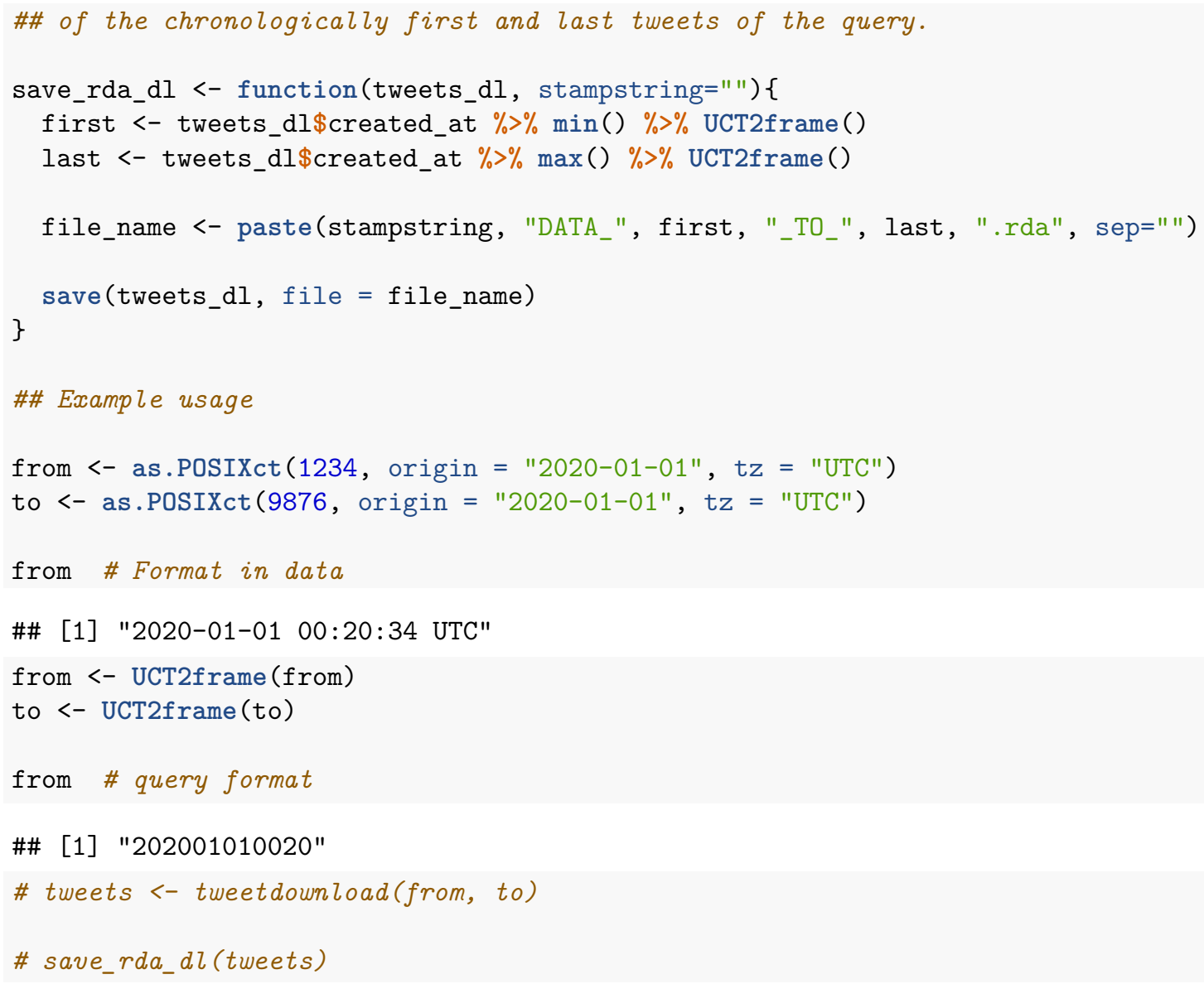

Calculating gaps in between Storify \#NGSSchat database

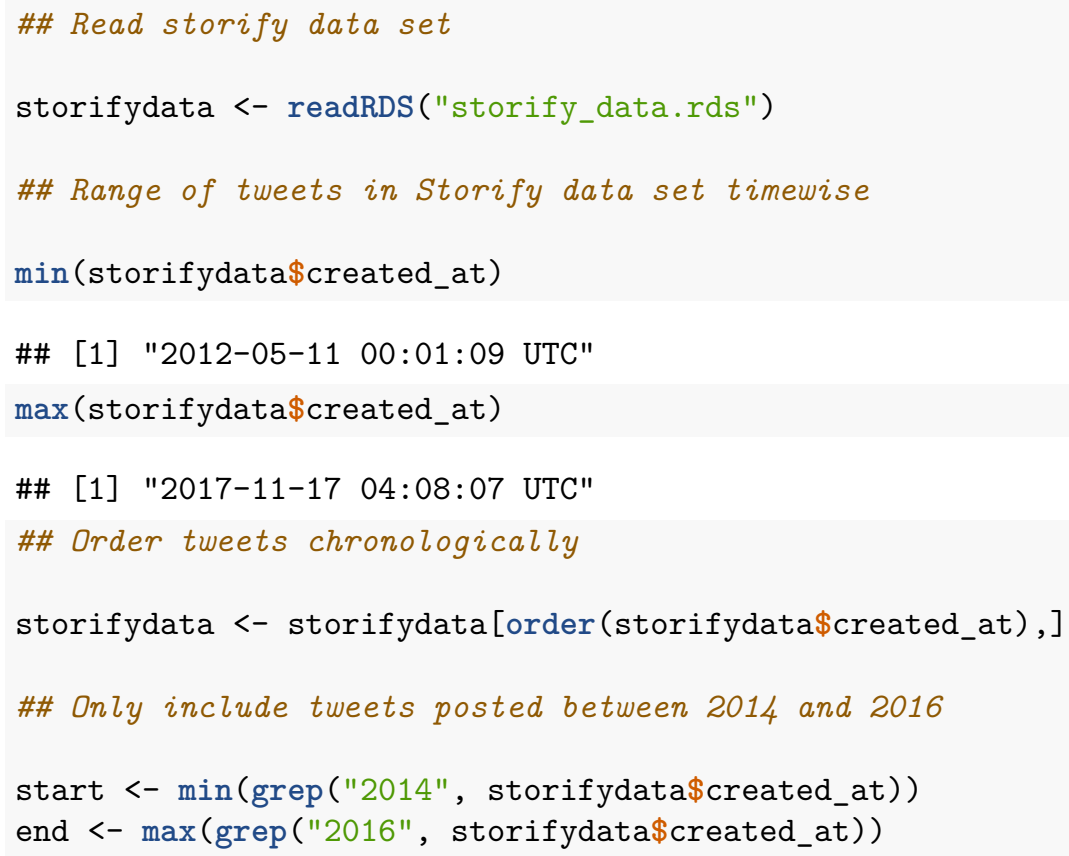




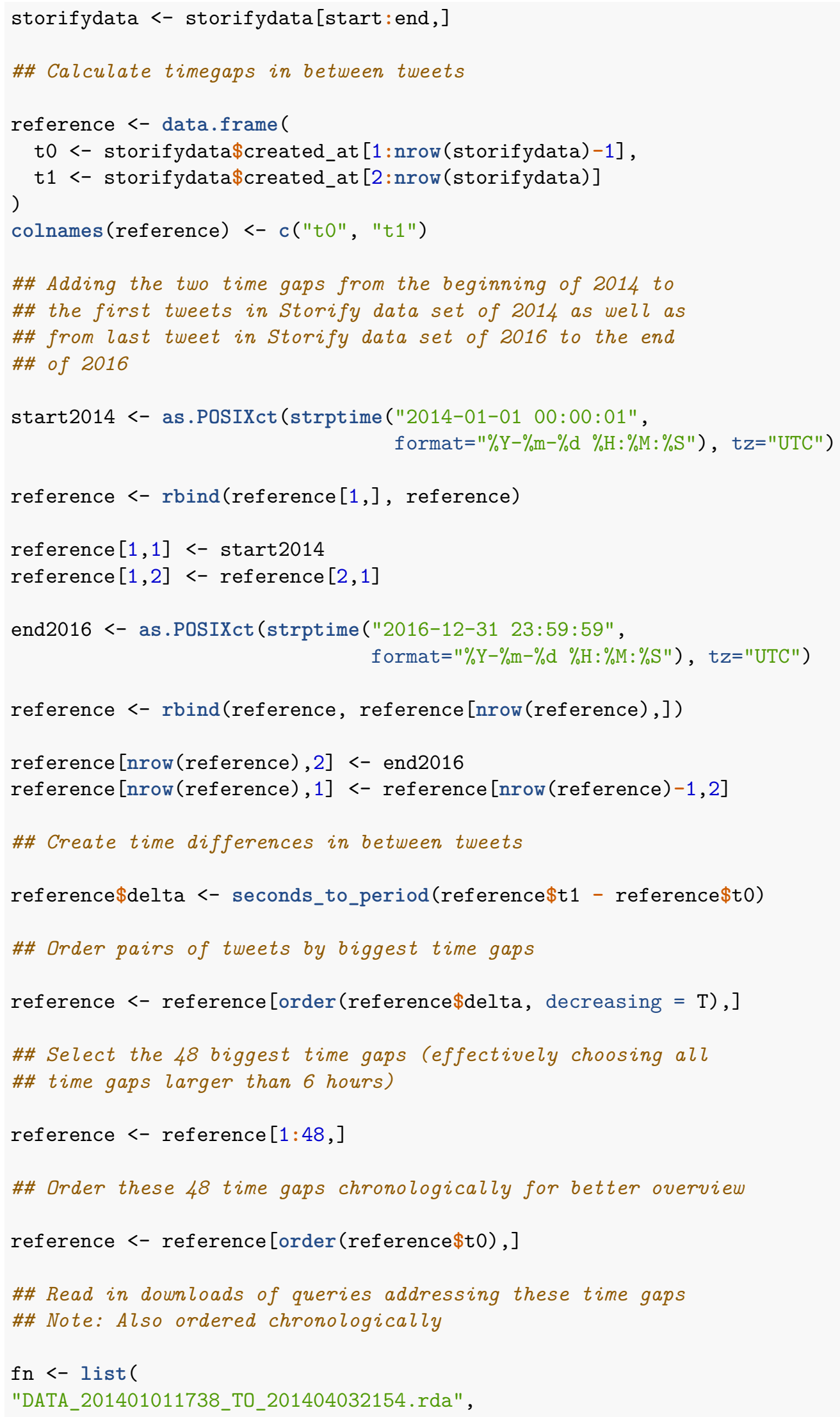


"DATA_201404040214_T0_201404180058.rda", "DATA_201404180247_TO_201405020054.rda", "DATA_201405020209_TO_201405160017.rda", "DATA_201405160207_T0_201405291751.rda", "DATA_201405300204_T0_201406130059.rda", "DATA_201406130213_T0_201406270054.rda", "DATA_201406270211_T0_201407101021.rda", "DATA_201407101310_T0_201407110048.rda", "DATA_201407110202_T0_201408010054.rda", "DATA_201408010243_T0_201408150059.rda", "DATA_201408150201_T0_201408280927.rda", "DATA_201408280947_TO_201408290020.rda", "DATA_201408290207_T0_201409120057.rda", "DATA_201410030134_T0_201410170056.rda", "DATA_201410170223_T0_201410292040.rda", "DATA_201410292101_T0_201410310059.rda", "DATA_201411070232_T0_201411141125.rda", "DATA_201411141412_T0_201411210159.rda", "DATA_201411210314_T0_201412050159.rda", "DATA_201412190303_T0_201501090159.rda", "DATA_201501230255_T0_201502060159.rda", "DATA_201503052243_T0_201503130039.rda", "DATA_201503131023_T0_201503200059.rda", "DATA_201503200223_TO_201504030059.rda", "DATA_201505270116_T0_201506050057.rda", "DATA_201506050240_T0_201506190059.rda", "DATA_201506190201_T0_201507030056.rda", "DATA_201507030211_T0_201507170058.rda", "DATA_201507170213_T0_201507310058.rda", "DATA_201507310230_T0_201508070057.rda", "DATA_201508070201_T0_201508210004.rda", "DATA_201508211409_T0_201509040100.rda", "DATA_201509040200_T0_201509180059.rda", "DATA_201509180200_T0_201510020056.rda", "DATA_201510020225_T0_201510160100.rda", "DATA_201510160942_T0_201511060154.rda", "DATA_201511061825_T0_201511200159.rda", "DATA_201511200307_T0_201512040200.rda", "DATA_201512040303_T0_201512180200.rda", "DATA_201512180306_T0_201601080159.rda", "DATA_201601080311_T0_201601220159.rda", "DATA_201601220356_T0_201602050201.rda", "DATA_201602051650_T0_201602190200.rda", "DATA_201602190314_TO_201603040159.rda", "DATA_201604251954_T0_201605060103.rda", "DATA_201605060227_T0_201605061332.rda", "DATA_201605061353_T0_201612312335.rda" )

\#\# While combining queries to new data frame, count \#\# number of new tweets per query in time gaps

all <- data.frame () 


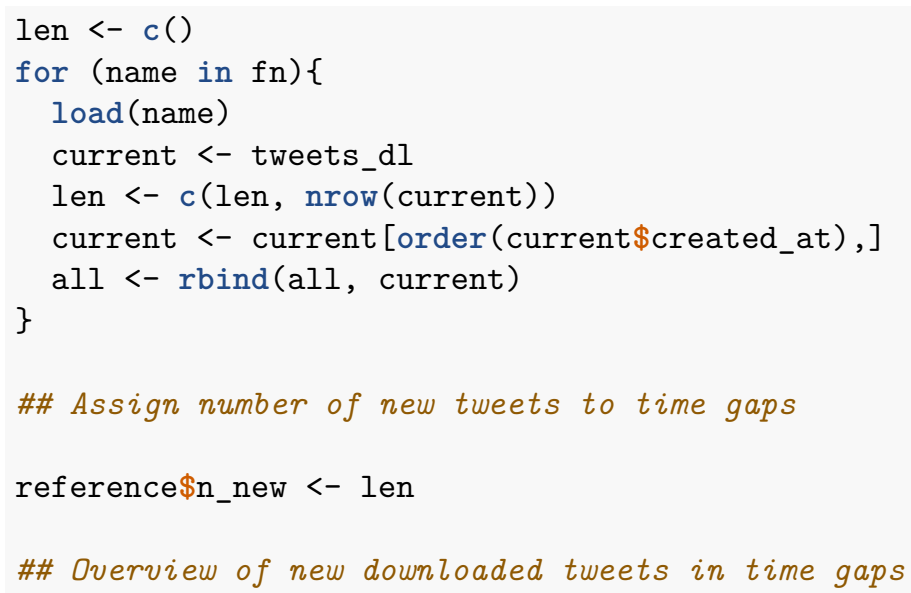




\begin{tabular}{|c|c|c|c|c|c|c|c|}
\hline \#\# & 12538 & $2015-10-16$ & $02: 18: 45$ & $2015-11-06$ & $02: 01: 57$ & $20 \mathrm{~d} 23 \mathrm{H} \quad 43 \mathrm{M} \quad 12 \mathrm{~S}$ & 500 \\
\hline \#\# & 13009 & $2015-11-06$ & $03: 05: 03$ & $2015-11-20$ & $02: 00: 52$ & $13 d \quad 22 \mathrm{H} 55 \mathrm{M} \quad 49 \mathrm{~S}$ & 500 \\
\hline \#\# & 13463 & $2015-11-20$ & $03: 07: 44$ & $2015-12-04$ & $02: 01: 01$ & 13d 22H 53M 17S & 430 \\
\hline \#\# & 13959 & $2015-12-04$ & $03: 03: 11$ & $2015-12-18$ & $02: 01: 12$ & $13 d \quad 22 \mathrm{H} 58 \mathrm{M} 1 \mathrm{~S}$ & \\
\hline \#\# & 14305 & $2015-12-18$ & $03: 06: 25$ & $2016-01-08$ & $02: 00: 23$ & $20 \mathrm{~d} 22 \mathrm{H} 53 \mathrm{M} 58 \mathrm{~S}$ & 3 \\
\hline \#\# & 14727 & $2016-01-08$ & $03: 02: 07$ & $2016-01-22$ & $02: 00: 42$ & $5 S$ & \\
\hline \#\# & 15215 & $2016-01-22$ & $03: 56: 12$ & $2016-02-05$ & $02: 02: 11$ & $13 d 22 \mathrm{H} 5 \mathrm{M} 59 \mathrm{~S}$ & 07 \\
\hline \#\# & 15932 & $2016-02-05$ & $16: 50: 37$ & $2016-02-19$ & $02: 01: 52$ & $13 d \quad 9 H \quad 11 M \quad 15 S$ & 9 \\
\hline \#\# & 16485 & $2016-02-19$ & $03: 14: 59$ & $2016-03-04$ & $02: 00: 08$ & $13 \mathrm{~d} 22 \mathrm{H} 45 \mathrm{M} 9 \mathrm{~S}$ & \\
\hline \#\# & 16946 & $2016-03-04$ & $03: 00: 05$ & $2016-05-06$ & $01: 04: 15$ & $62 \mathrm{~d} 22 \mathrm{H} \quad 4 \mathrm{M} \quad 10 \mathrm{~S}$ & \\
\hline \#\# & 17224 & $2016-05-06$ & $02: 27: 31$ & $2016-05-06$ & $13: 35: 40$ & $11 \mathrm{H} 8 \mathrm{M} 9 \mathrm{~S}$ & \\
\hline \#\# & 172261 & $2016-05-06$ & $13 \cdot 53 \cdot 14$ & $2016-12-31$ & $23: 59: 59$ & 239d $10 \mathrm{H} 6 \mathrm{M} 45 \mathrm{~S}$ & \\
\hline
\end{tabular}

\#\# [1] 17226

nrow(all) \# Sum of downloaded tweets in time gaps

\#\# [1] 33097

\section{Analysis of tweets downloaded between gaps in Storify \#NGSSchat database}

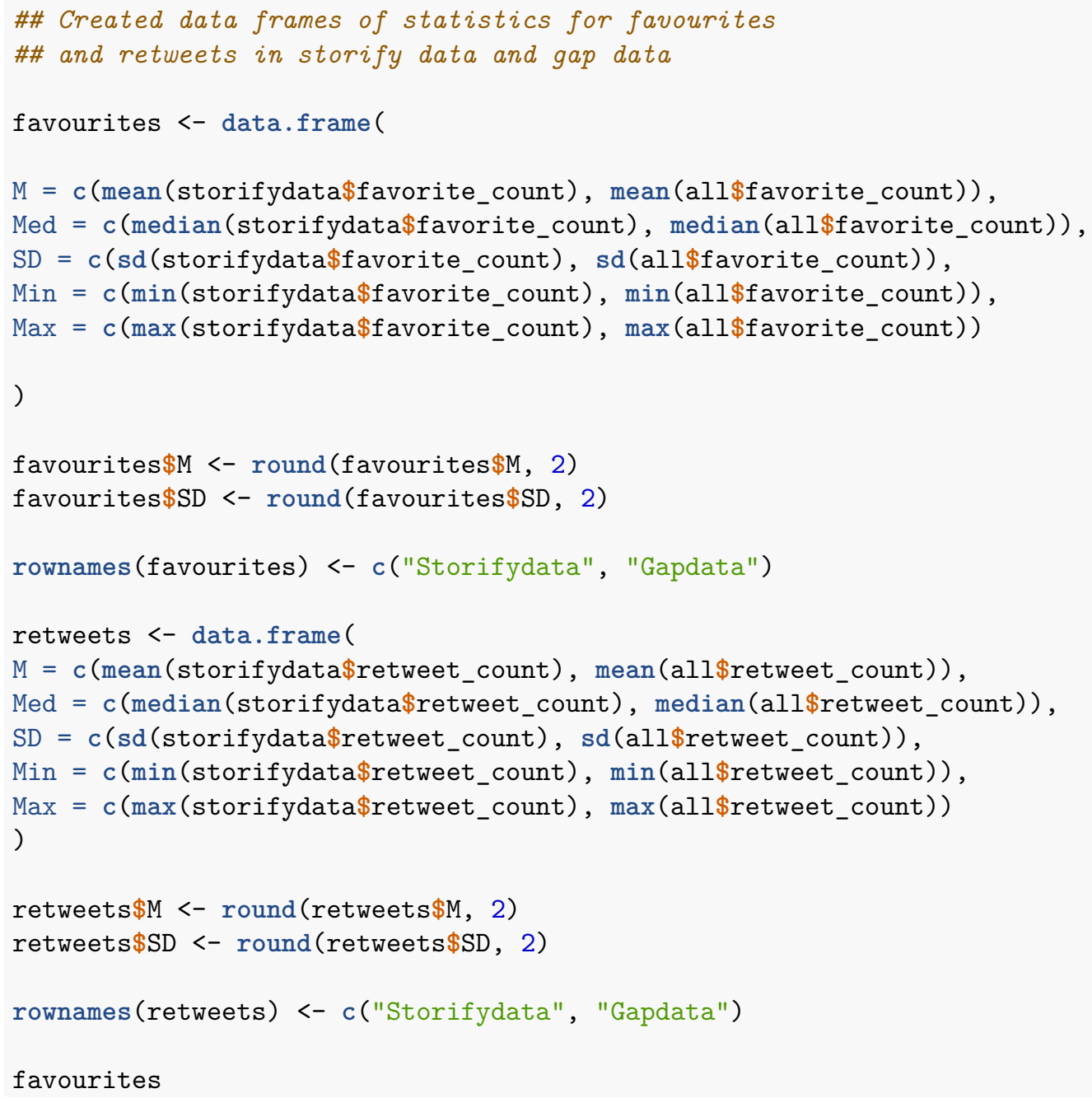




$\begin{array}{lrrrrrr}\text { \#\# } & & \text { Med } & \text { SD } & \text { Min } & \text { Max } \\ \text { \#\# Storifydata } & 1.20 & 1 & 1.75 & 0 & 38 \\ \text { \#\# Gapdata } & 0.93 & 0 & 2.66 & 0 & 248 \\ \text { retweets } & & & & & \\ & & & & & & \\ \text { \#\# } & \text { Med } & & \text { SD } & \text { Min } & \text { Max } \\ \text { \#\# Storifydata } & 0.35 & 0 & 1.04 & 0 & 53 \\ \text { \#\# Gapdata } & 0.43 & 0 & 1.93 & 0 & 198\end{array}$

\section{Selecting tweets within rush hours to re-download and compare}

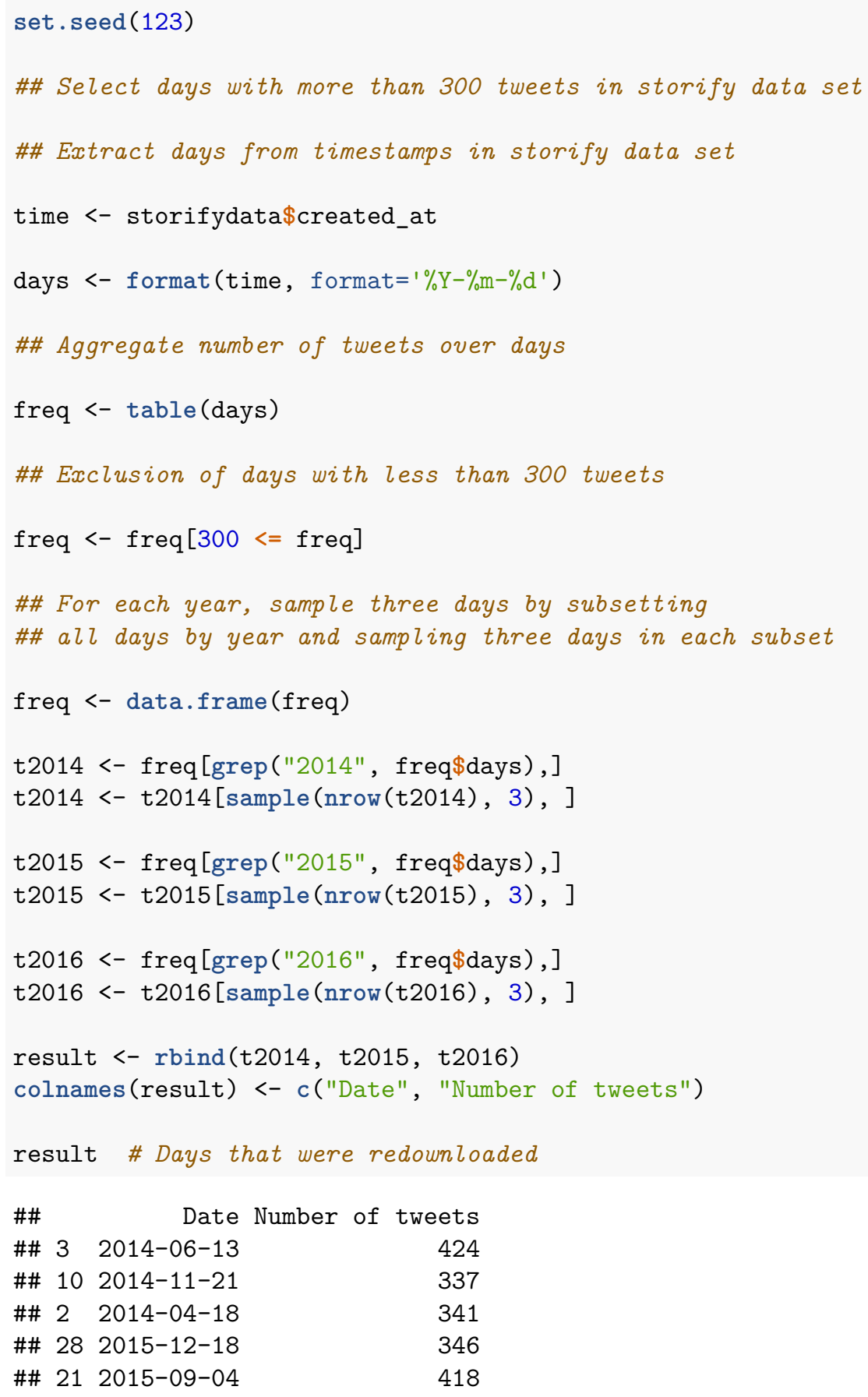




$\begin{array}{llll}\# \# & 15 & 2015-06-05 & 592 \\ \# \# & 32 & 2016-02-19 & 553 \\ \# \# & 30 & 2016-01-22 & 488 \\ \# \# & 33 & 2016-03-04 & 461\end{array}$

\section{Comparing re-downloaded tweets with the Storify \#NGSSchat database}

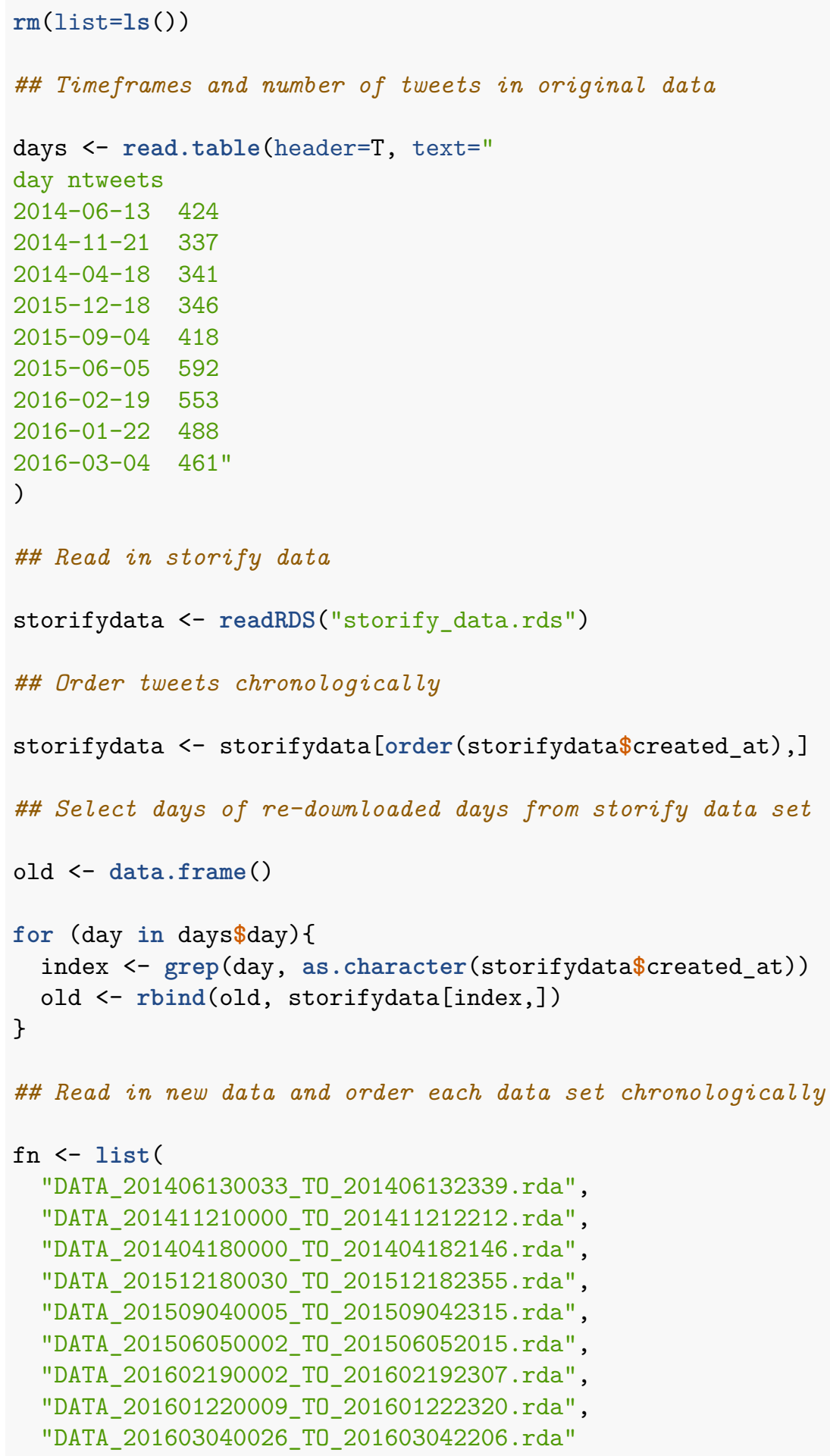




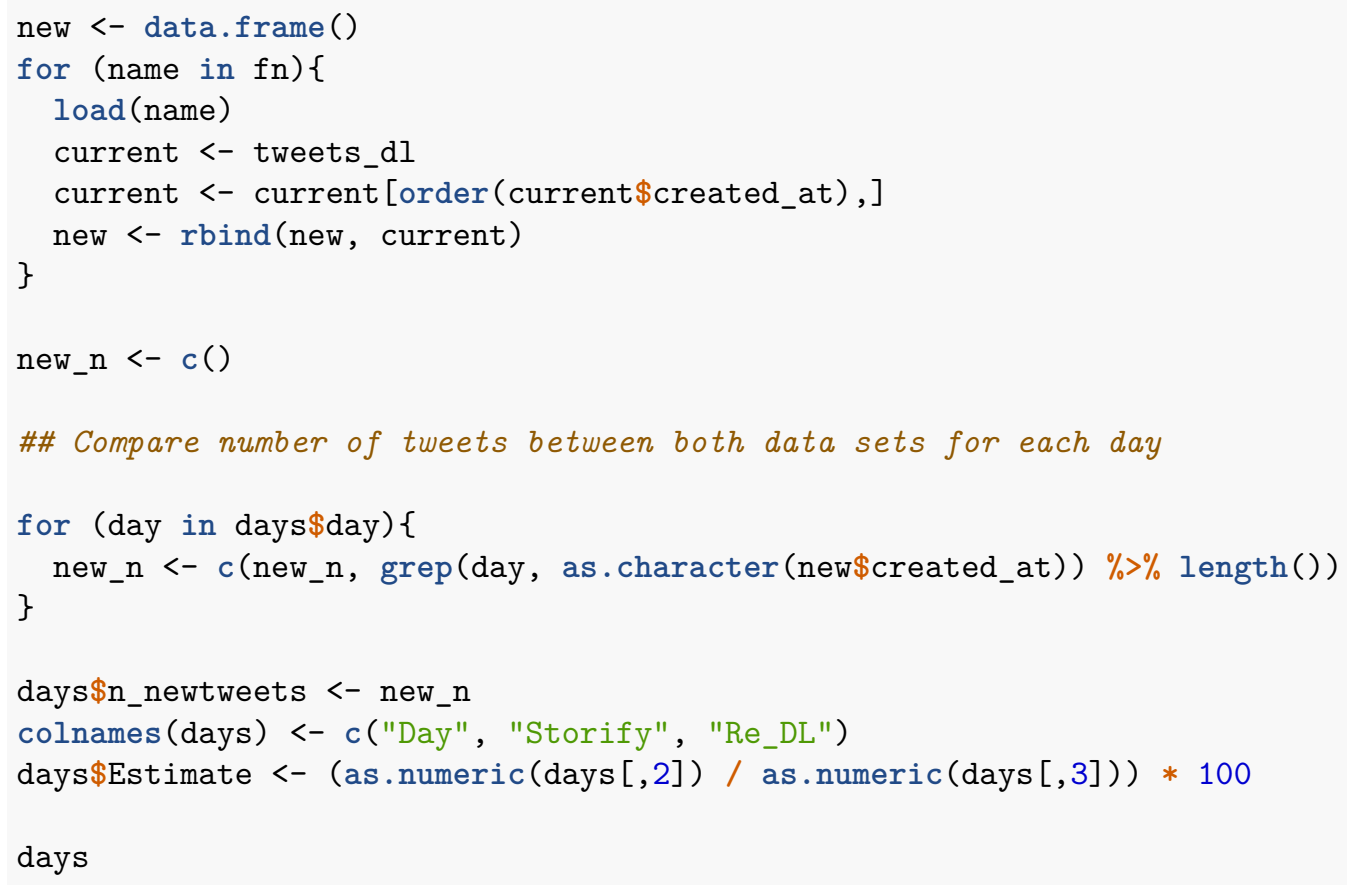

Have tweets been deleted since the download of the storify data set?

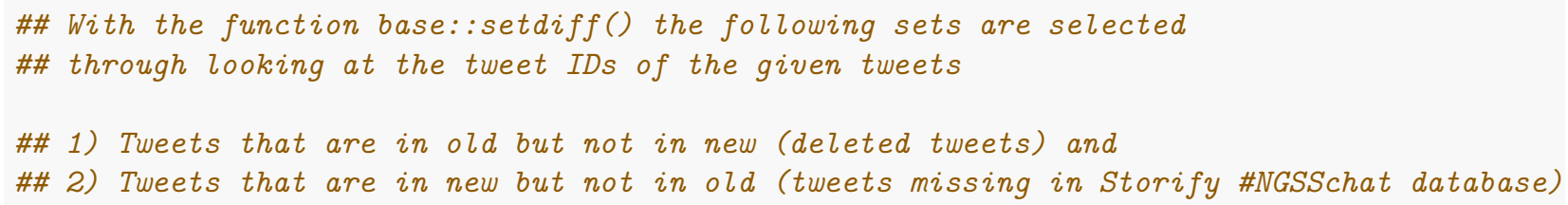




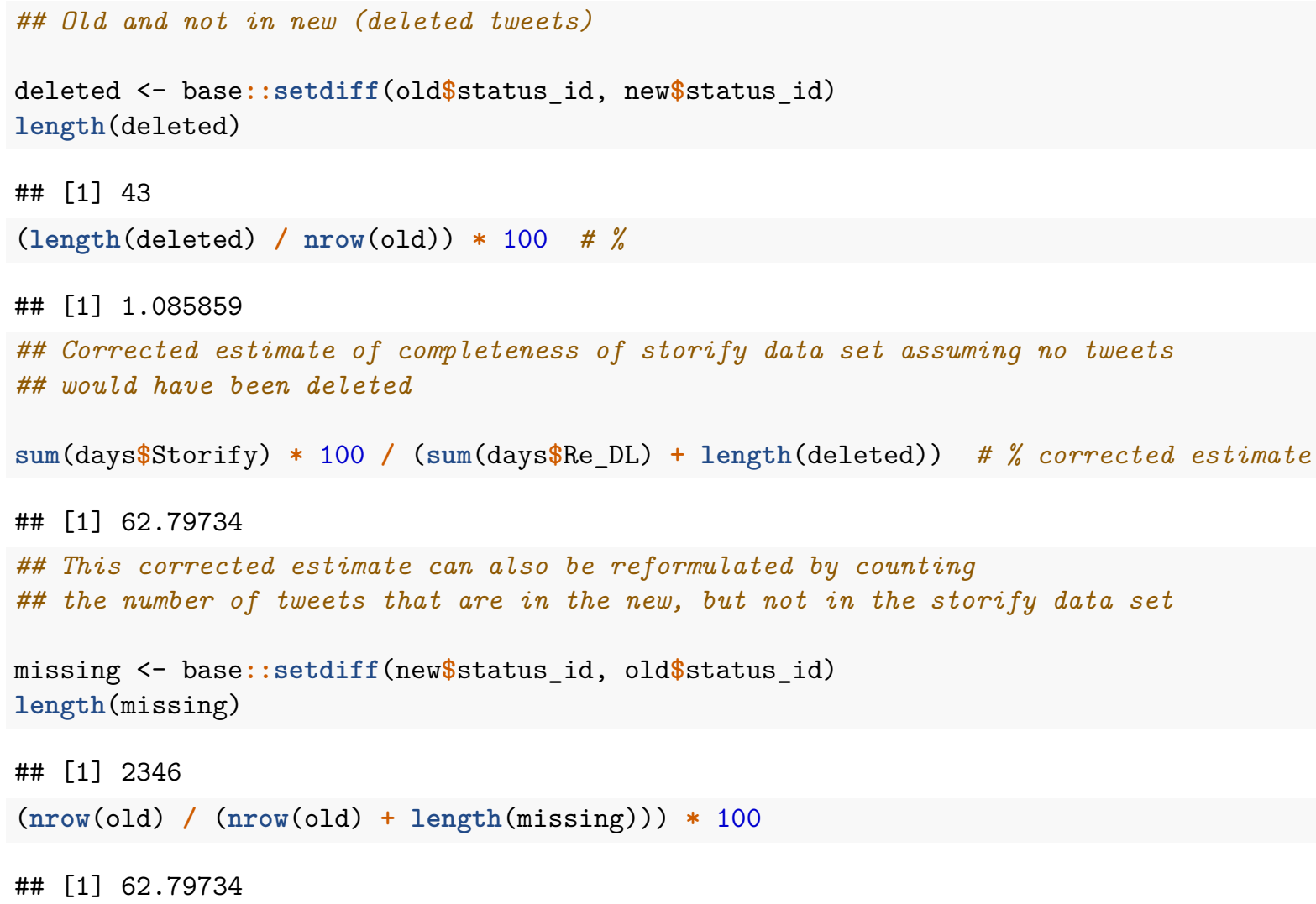

Which kind of data within rush hours misses in the Storify \#NGSSchat database?

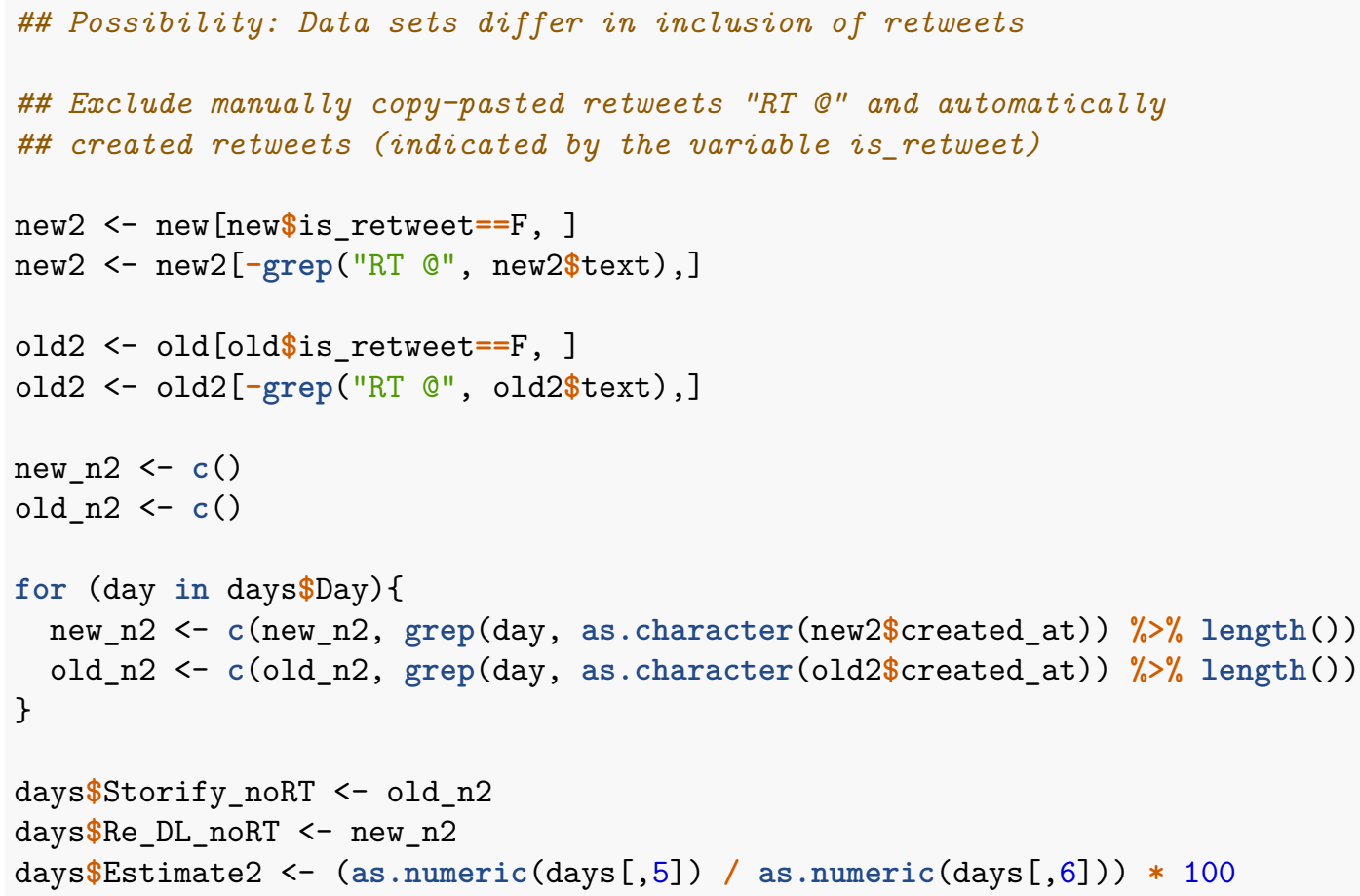




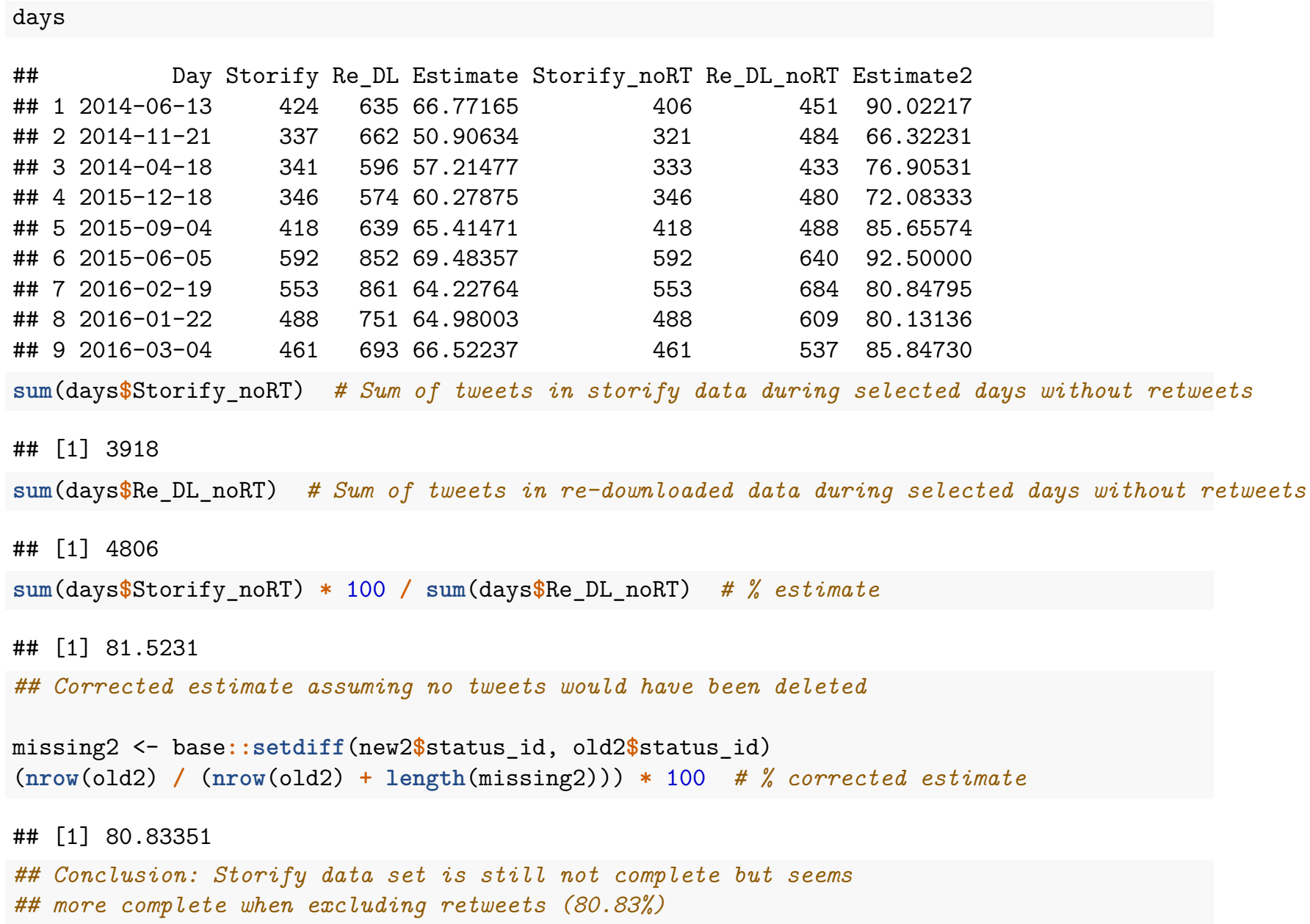

\section{Is the storify data set complete during the most busy hours of \#NGSSchat?}

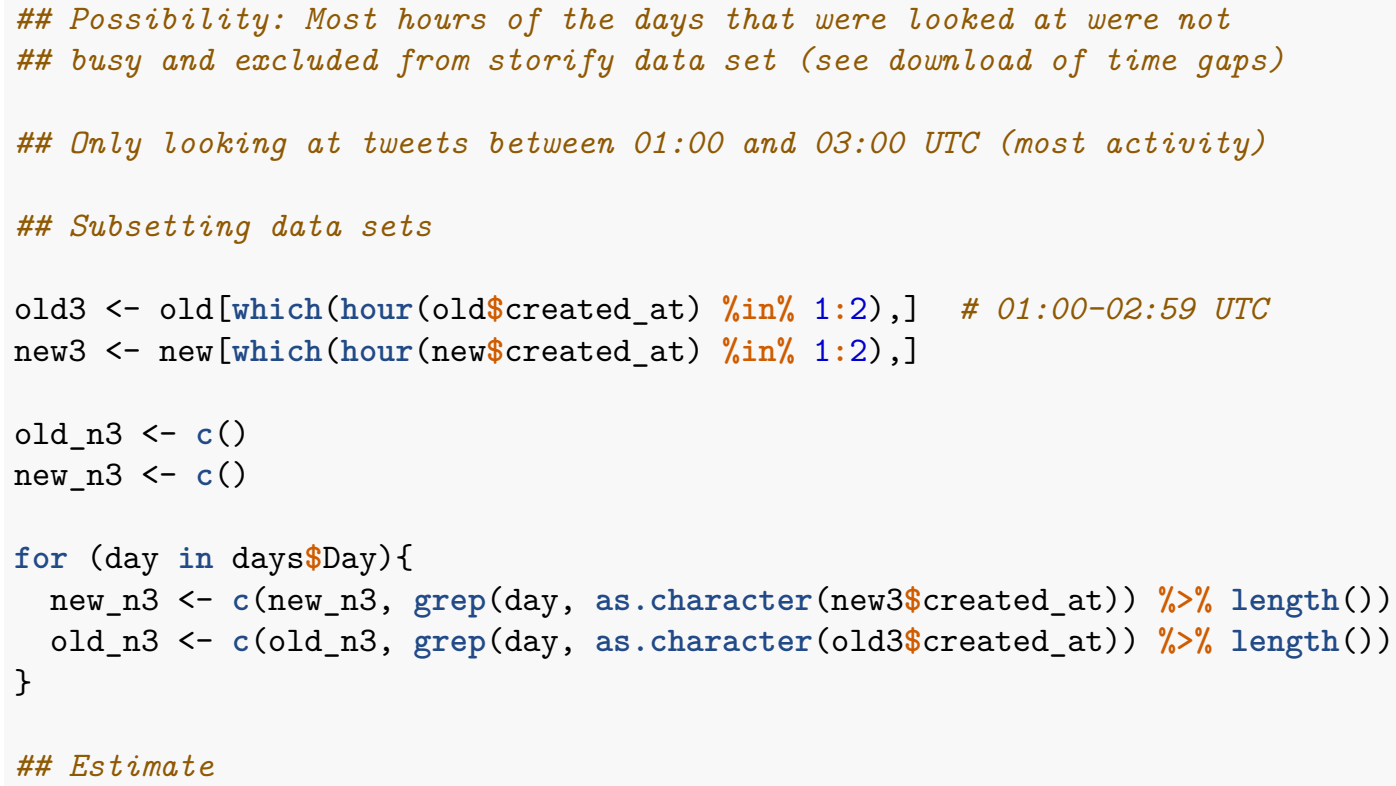




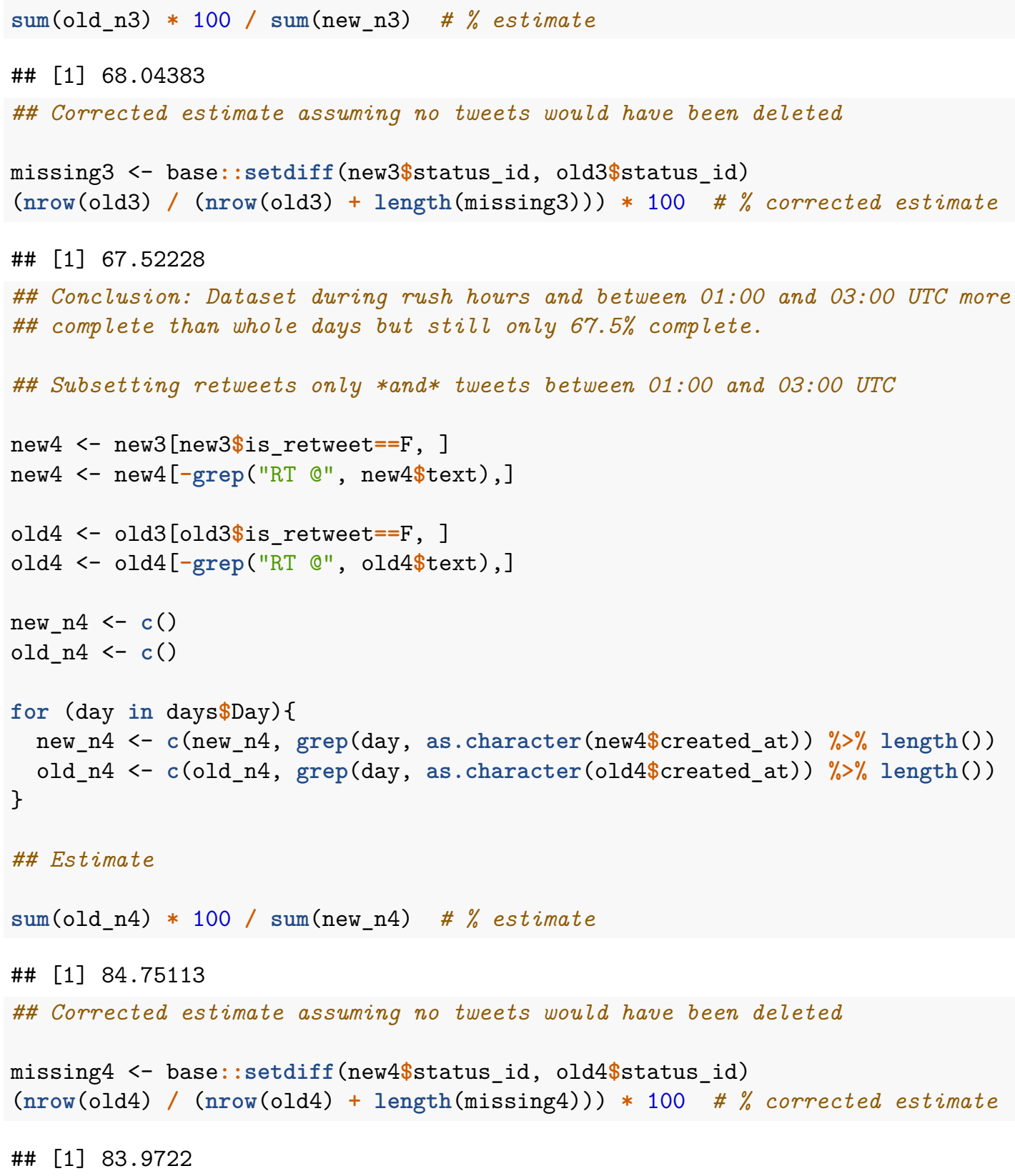

\section{Summary of estimates of completeness of Storify data set within NGSS chat sessions}

The storify data is incomplete within rush hours. The share to which the storify data set is complete increases slightly when only looking at data during the most busy hours and increases drastically when excluding retweets. This points to the fact that different exclusion criteria were applied. Futhermore, the data is incomplete to similar degrees between all re-downloaded days.

\#\# All estimates

\#\# All data

days $[1: 4]$ 


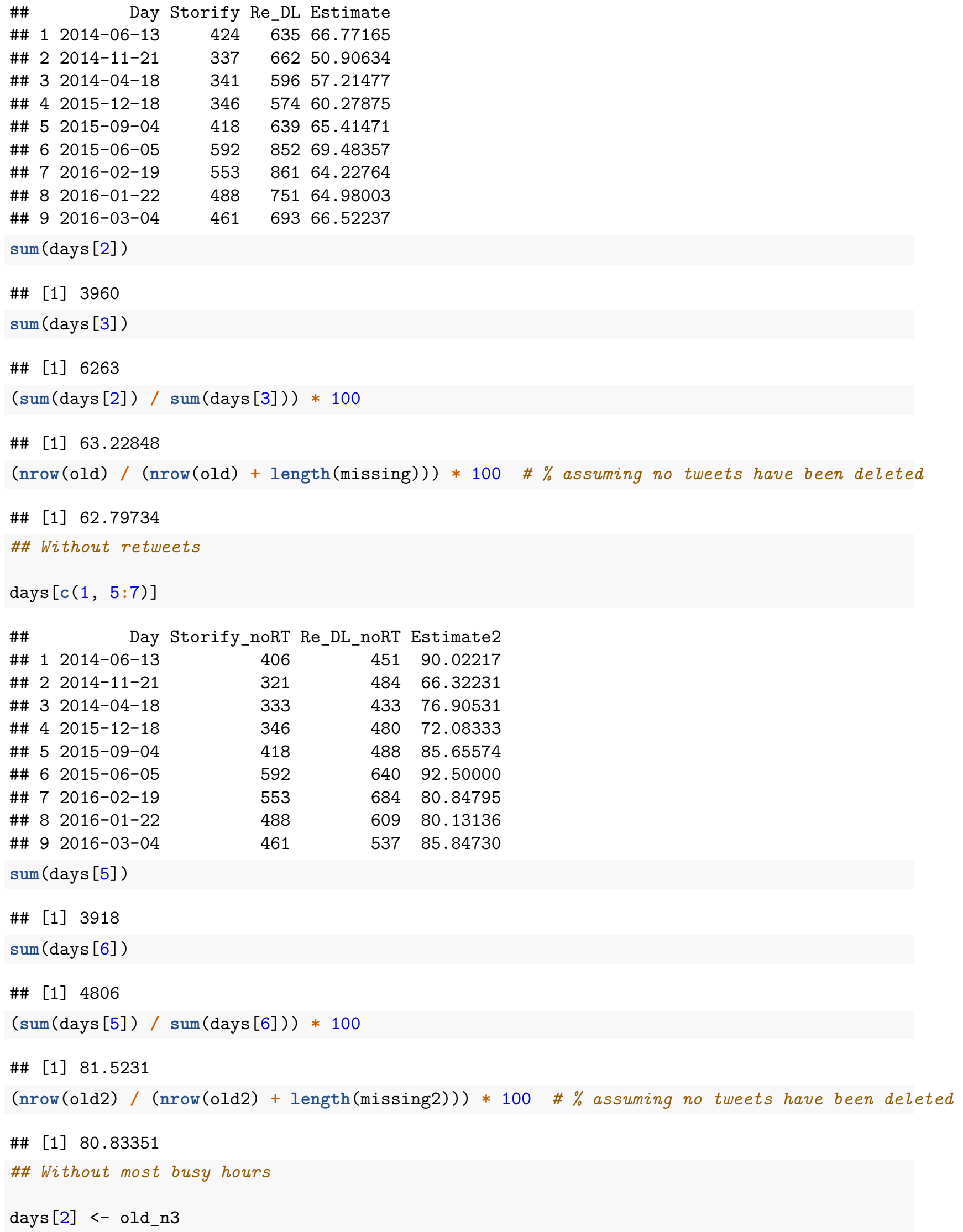




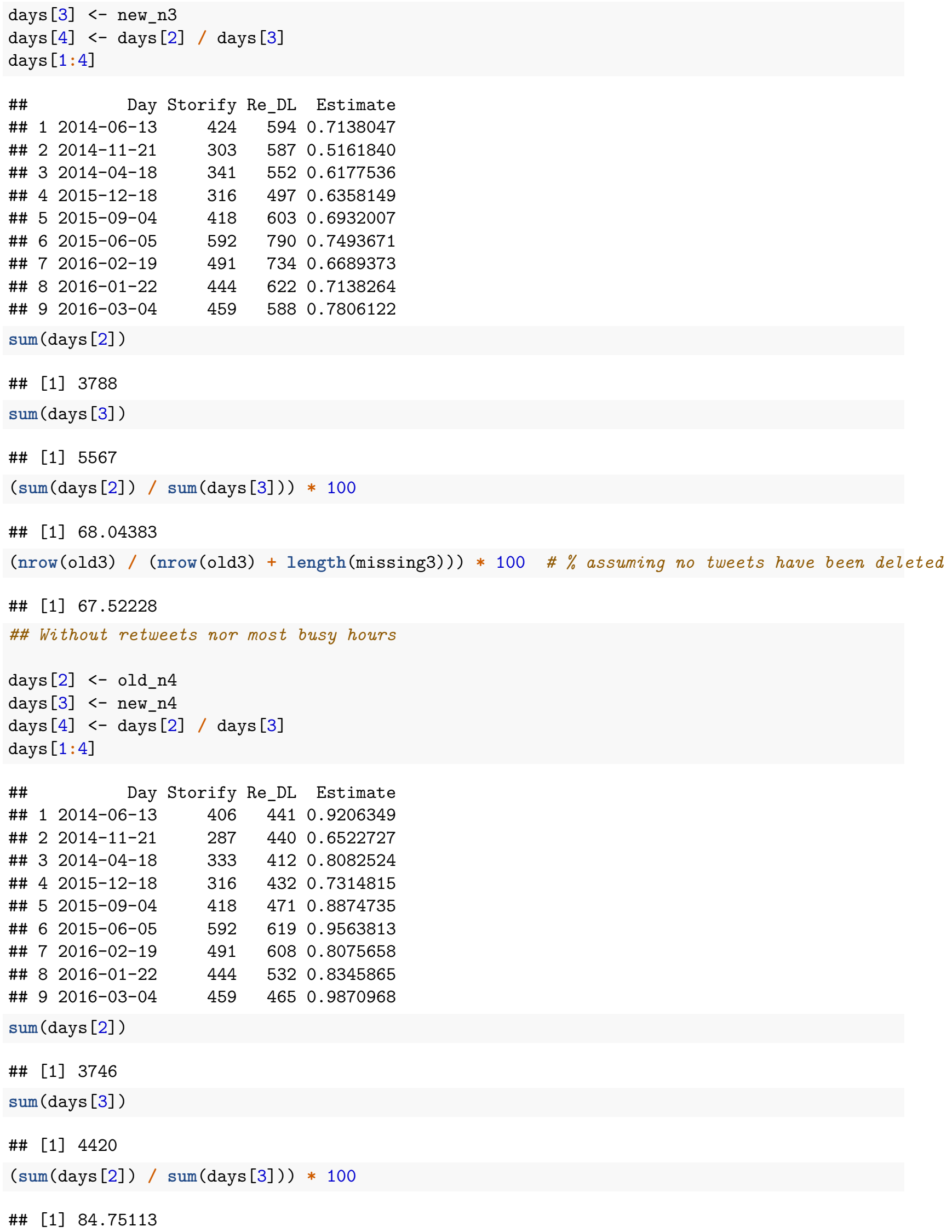




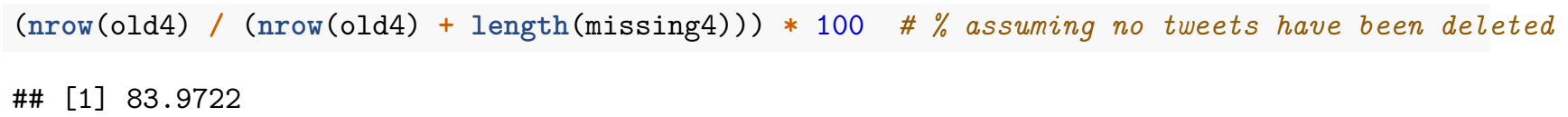

\section{Considering different possible criteria of exclusion by Storify administrators}

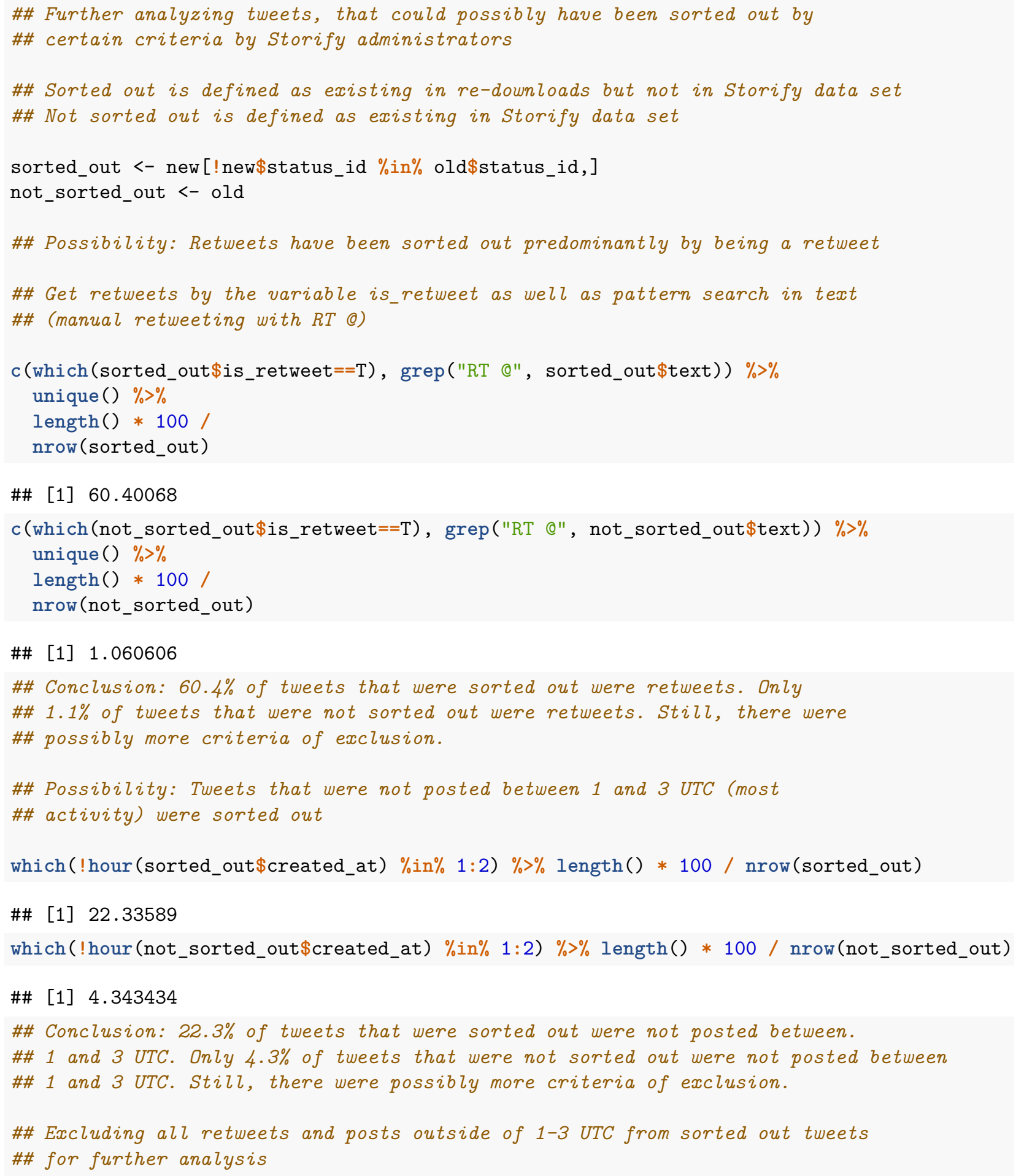




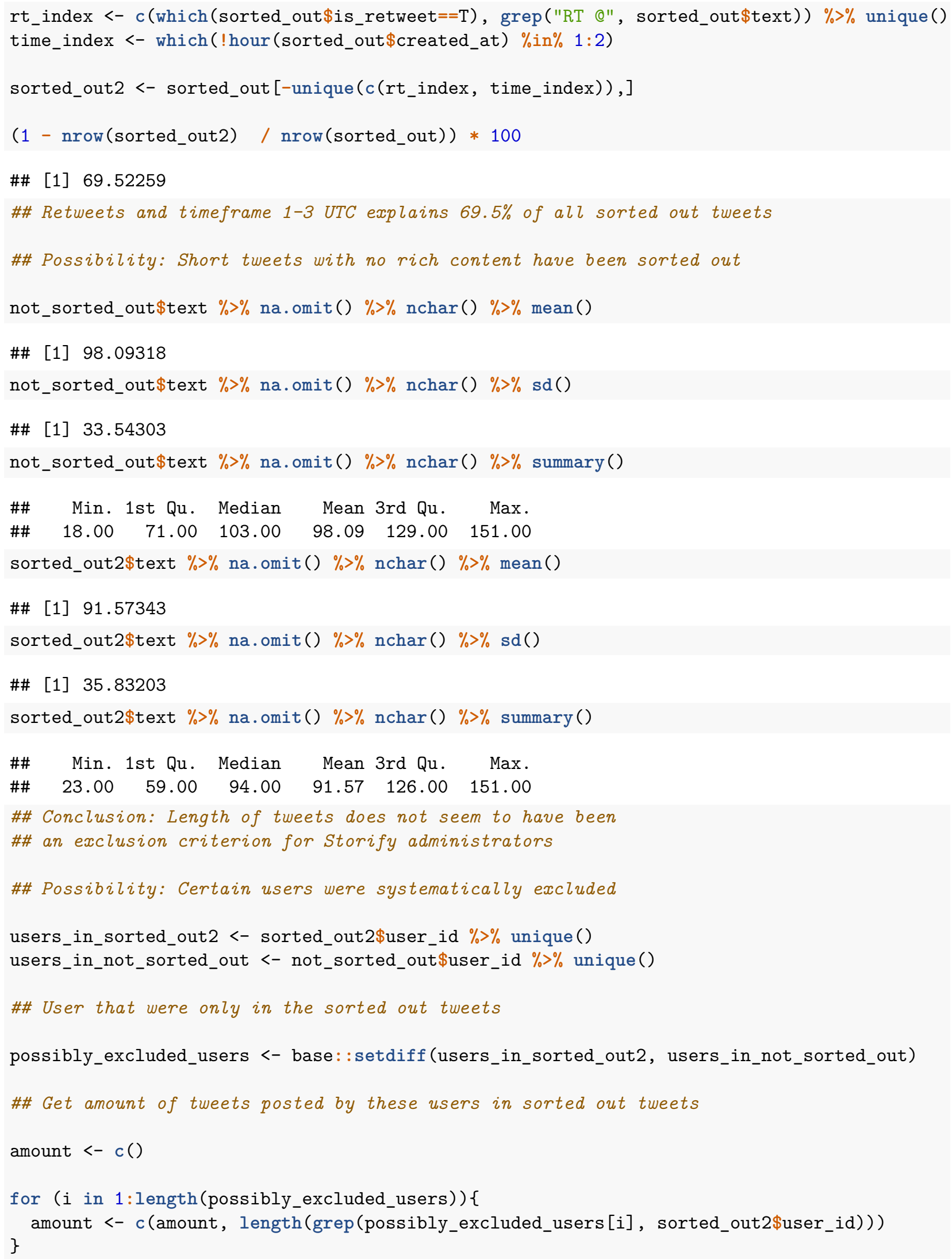




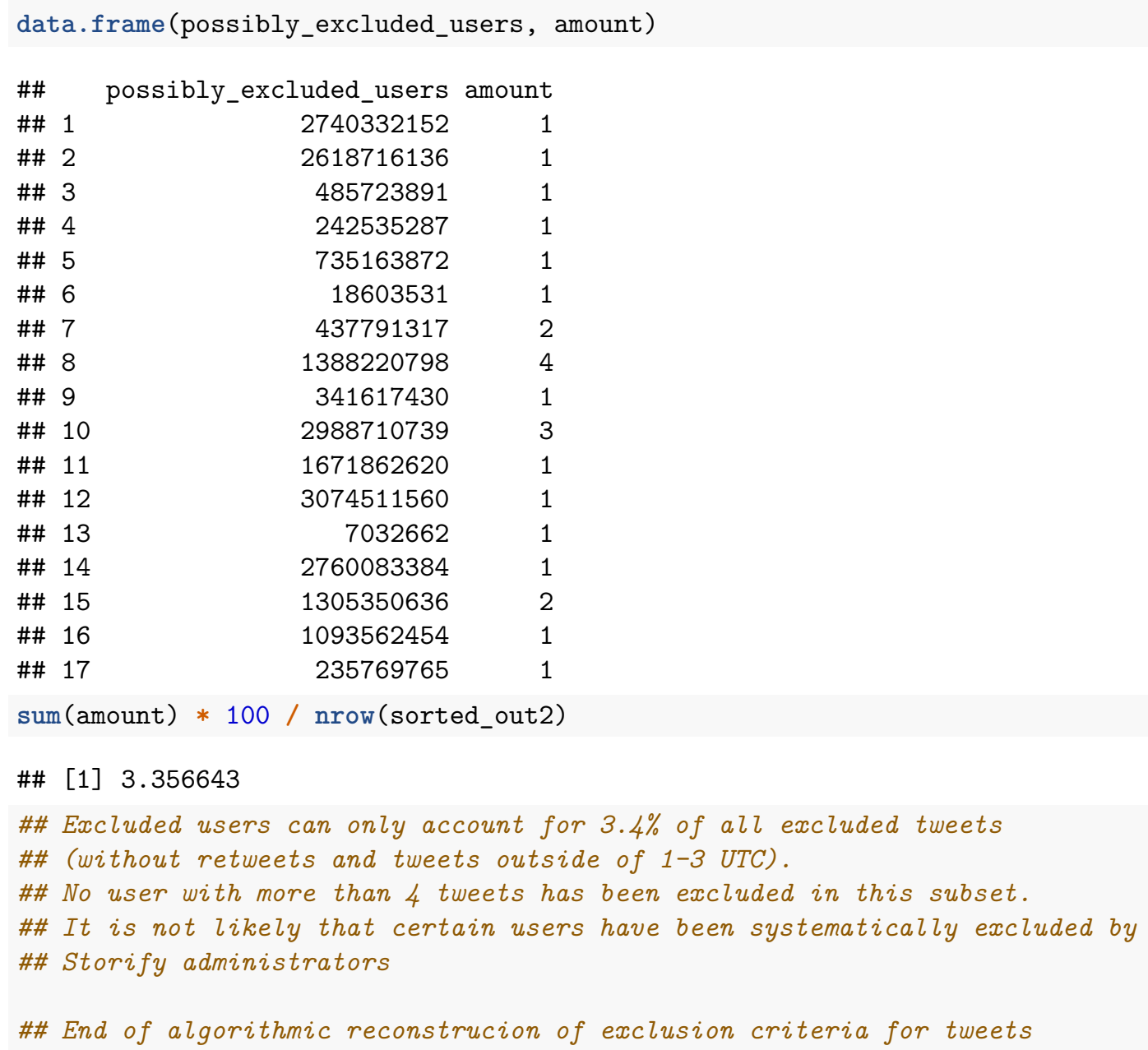

